\title{
The incidence of germinal centres in thymus glands of patients with congenital heart disease
}

\author{
J. M. VETTERS AND R. S. BARCLAY \\ From the University of Glasgow, Department of Pathology, Western Infirmary, Glasgow, and the \\ Thoracic Unit, Mearnskirk Hospital, Glasgow
}

SYNOPSIS The incidence of thymic germinal centres in normal individuals is disputed by various authors. The present study gives the results of a detailed histological assessment of 75 thymic biopsies obtained during operations to correct congenital heart lesions. Serial sectioning showed structures previously of disputed significance to be obliquely sectioned germinal centres. Comparison with the data of Hammar (1926) showed that there was some stress involution of the glands studied. Despite this $40 \%$ of the subjects had thymic germinal centres. Germinal centres were not detected in subjects under 4 years of age and there were insufficient subjects over 16 years of age to allow assessment of the frequency in adult thymus glands.

It is now recognized that the thymus is involved both in the maintenance of immune competence and the genesis of autoimmune diseases. Consequently, much attention has been paid to thymic histology in diseases, such as myasthenia gravis, in which thymic germinal centres are common. However, information on the incidence of germinal centres in the thymus gland of normal individuals is fragmentary and often contradictory (table I).

The descriptive terms used in the publications on this subject vary and it is clear that similar terms are used to refer to different types of structure. Where reference is made to another publication the descriptive term employed, 'lymphoid follicle', 'germinal centre', etc, is that used by that author; the definitions stated by the various authors are given in the discussion.

Although Sloan (1943) described thymic germinal centres in approximately $10 \%$ of a group of subjects who died suddenly, Castleman and Norris (1949), Anderson (1956), Burnet (1962), and Burnet and Mackay (1965) stated that thymic germinal centres did not occur in normal subjects. Interest in the topic was rekindled in 1967 by Middleton's observation that $51 \%$ of a group of patients dying shortly after accidents had structures in the thymus which he identified as lymphoid follicles (the incidence in subjects under 40 years of age was $72 \%$ ). Middleton also noted that subjects who died after a terminal illness of less than three days' duration had a much Received for publication 1 June 1973. higher incidence of thymic lymphoid follicles than those who had more protracted illnesses. Middleton also stated that many of the thymic lymph follicles detected in accidentally killed subjects were of the same size as those found in thymus glands removed surgically from patients with myasthenia gravis.

Studies of patients with congenital heart diseases by Bhathal and Campbell (1965) and by Henry (1968) have reported germinal centres in approximately $20 \%$ of individuals. However, Goldstein and Mackay (1967) in a study of thymus glands similarly biopsied during operations to correct congenital heart lesions or obtained at necropsy after brief illnesses detected thymic germinal centres in only two of 94 individuals. Okabe (1966) detected only 18 subjects with thymic germinal centres in a study of 1356 necropsies whilst Habu, Kameya, and Tamaoki (1972) detected thymic lymph follicles in approximately $17 \%$ of subjects dying rapidly from accidental causes.

The present study was performed in an attempt to resolve these widely divergent findings and to determine the following points: (1) Do the thymus glands of patients with congenital heart disease show stress involution, ie, do the percentages of the glands occupied by cortex and medulla differ from Hammar's (1926) data on normal subjects? (2) In what proportion of patients operated on for congenital heart disease are germinal centres present in the thymus gland? (3) Does the age affect the incidence of thymic germinal centres? 


\begin{tabular}{|c|c|c|c|}
\hline Author & Incidence & Nomenclature & How Material Acquired \\
\hline Anderson (1956) & $0 / 20$ & Germinal centre & No details \\
\hline Blathal and Campbell (1967) & $\begin{array}{l}4 / 20 \\
0 / 160\end{array}$ & Germinal centre & $\begin{array}{l}\text { Operations to correct congenital heart disease } \\
\text { Necropsy }\end{array}$ \\
\hline Goldstein and Mackay (1965) & $0 / 14$ & Germinal centre & Necropsy: cases include treated leukaemia patients \\
\hline Goldstein and Mackay (1967) & $\begin{array}{l}2 / 94 \\
0 / 104\end{array}$ & Germinal centre & $\begin{array}{l}\text { Necropsy }<24 \text { hours after death } \\
\text { Necropsy }>7 \text { days after death }\end{array}$ \\
\hline Habu et al (1971) & $12 / 71$ & Lymphoid follicles & Necropsy: accidental deaths \\
\hline Henry (1968) & $13 / 62$ & Germinal centre & Operations to correct congenital heart disease \\
\hline Middleton (1967) & $\begin{array}{l}36 / 71 \\
18 / 58 \\
21 / 648\end{array}$ & Lymphoid follicles & $\begin{array}{l}\text { Necropsy: sudden death } \\
\text { Necropsy: }<3 \text { days' illness } \\
\text { Necropsy: }>3 \text { days' illness }\end{array}$ \\
\hline Okabe (1966) & $18 / 1356$ & Germinal centre & Necropsy \\
\hline Sloan (1943) & $\begin{array}{r}14 / 150 \\
0 / 200\end{array}$ & Germinal centre & $\begin{array}{l}\text { Necropsy: sudden deaths } \\
\text { Necropsy: hospital deaths }\end{array}$ \\
\hline
\end{tabular}

Table I Incidence of reactive lymphoid structure in 'normal' thymus glands

\section{Materials and Methods}

Biopsies were obtained from 75 patients during operations to correct congenital heart disease. Cases of rheumatic heart disease were excluded because rheumatic fever is believed to have an immunological basis. The ages of the subjects ranged from 13 days to 39 years of age; 36 were males. The age and sex distributions are shown in figure 1.

The operations took place between November 1968 and February 1971.

\section{Technical Methods}

PROCESSING FOR HISTOLOGICAL

EXAMINATIONS

All thymic tissue was placed in $10 \%$ formol saline immediately after excision. After fixation blocks were trimmed, processed, and embedded in paraffin wax using conventional techniques. Sections were cut at $6 \mu$ thickness and stained with haemalum and eosin.

\section{MENSURATION}

The proportions of each thymus gland occupied by cortex, medulla, and interstitial tissue were determined by point counting. The minimum number of points counted in any case was 500 . If the tissue sections were too small the slides were turned roundo and recounted and the two scores summaterl.

An outline drawing of each histological section was obtained using a Wild M20 microscope witho drawing tube. The apparatus was calibrated to gives a linear magnification of $\times 10$. The area of each outline drawing was determined with a Haff $317^{\circ}$ planimeter.

Each section was systematically scanned using the $\times 10$ objective. Germinal centres were identified by the following criteria: large pale cells in a discrete massō in which mitotic figures and phagocytosed nuclearo debris (tingible bodies) were identified. The cluster of pale cells was usually surrounded by a cuff of lymphocytes (see figs 2 and 6).

In addition to classical germinal centres, other? structures were present in the medulla which had? some of the features of germinal centres. Various authors have interpreted these structures dif ferently and have used different names; in this study 3 to avoid confusion they have been called 'rounded lymphoid clusters' (see figs 3-5).

Three appearances were recognized: (1) Sharply circumscribed clusters of lymphocytes, the peri- 은 pheral cells of which were in clearly defined rows. ( 2 票

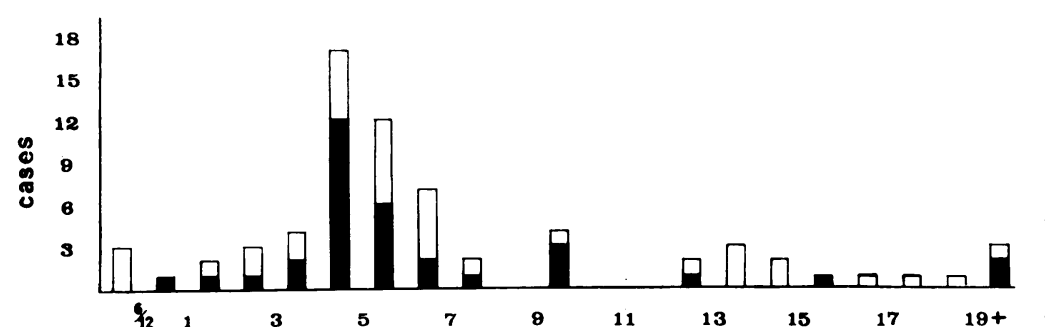

age
Fig 1 Age and sex distribution. The ages and sexes of the 75 subjects in the series are shown. Only 36 were males and most subjects were between 4 and 7 years of age. 


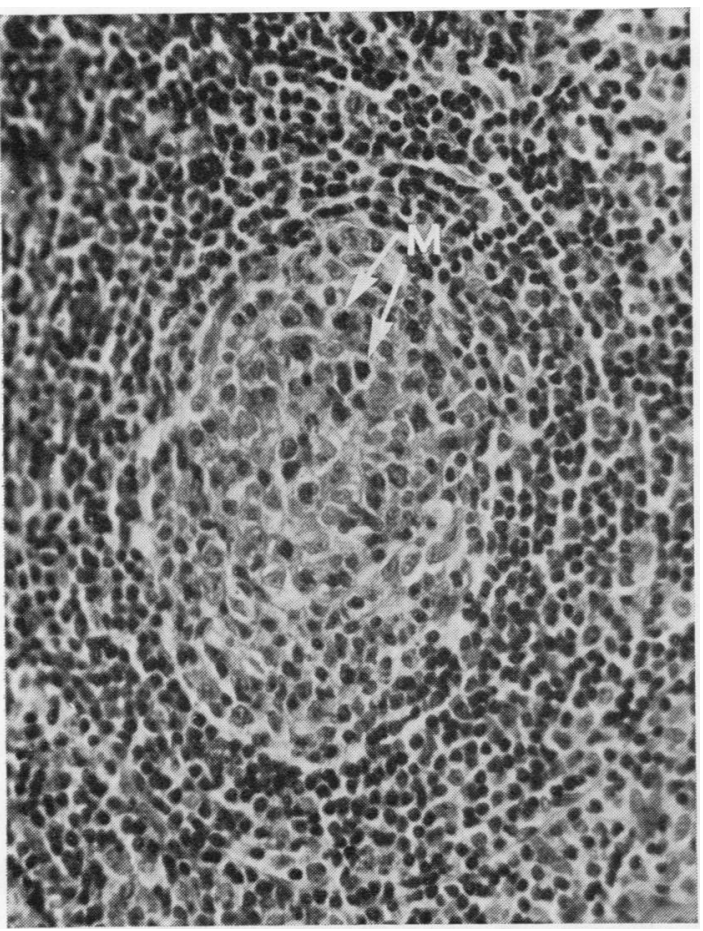

Fig 2

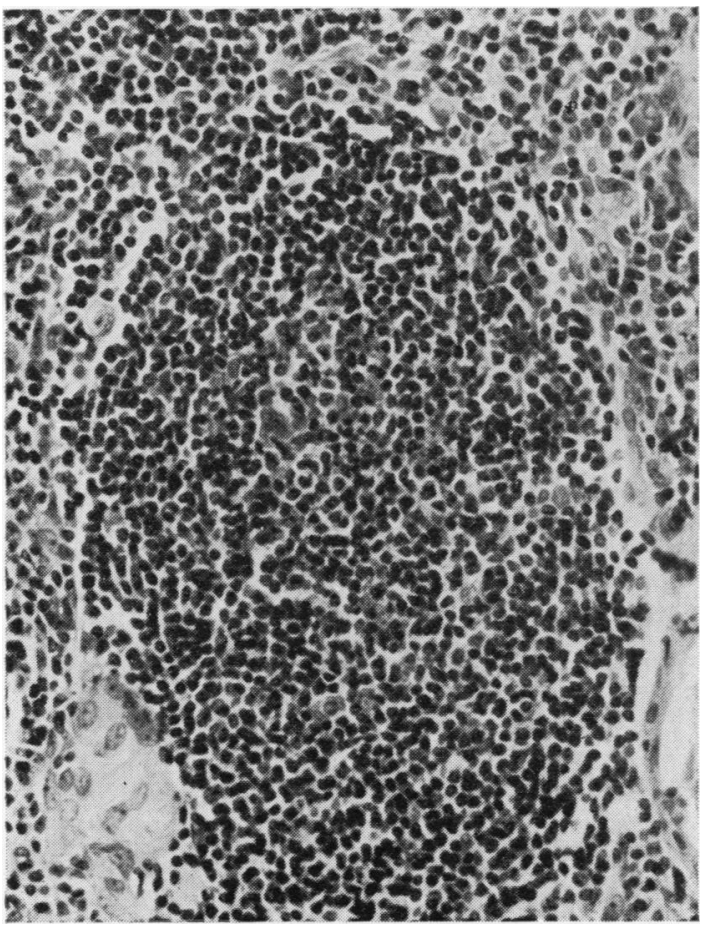

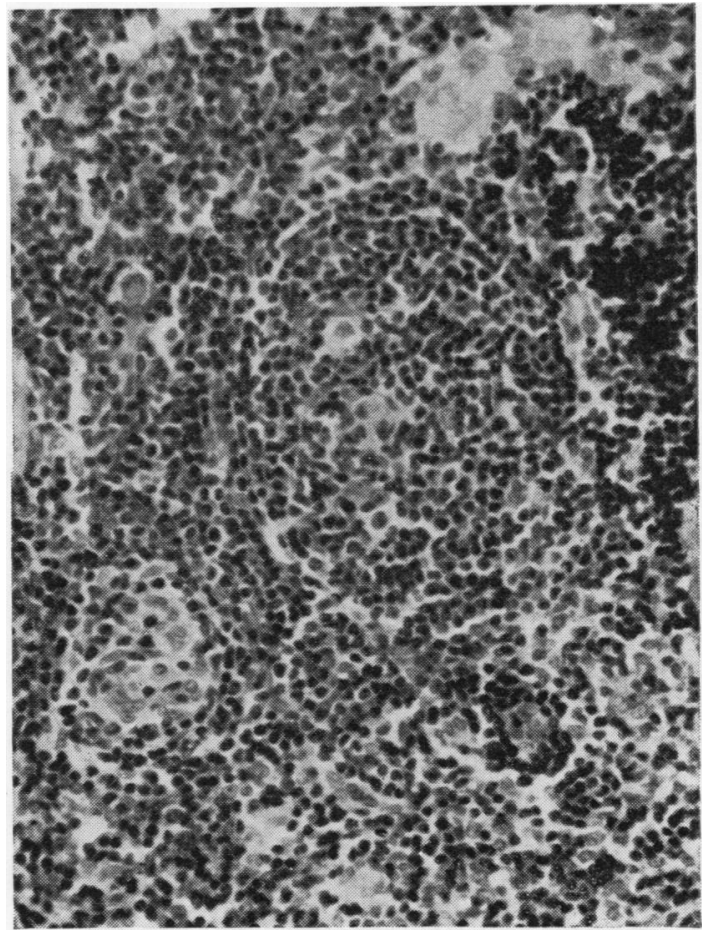

Fig 4

Fig 2 Germinal centre. The lymphocytic cuff surrounding the pale central cluster of reticulum cells and macrophages is clearly seen. The pale centre contains mitotic figures $(\mathrm{M})$ and tingible bodies. $H E \times 400$.

Fig 3 Rounded lymphoid cluster. This consists of a large dense cluster of lymphocytes. HE $\times 400$.

Fig 4 Rounded lymphoid cluster. In this example small numbers of large pale reticulum cells are present in the cluster of lymphocytes. $\mathrm{HE} \times 250$.

Fig 3 


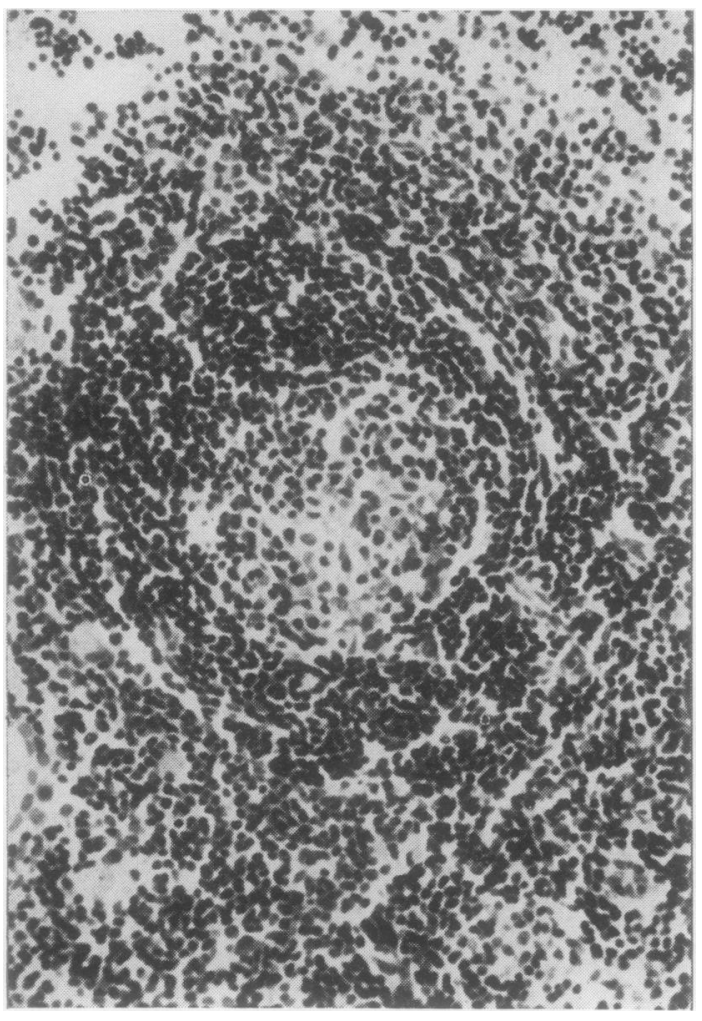

Fig 5 Rounded lymphoid cluster. Here there is a well defined lymphocytic cuff with a pale centre but no mitotic figures or tingible bodies are present. HE $\times 250$.

Clusters of lymphocytes in the centre of which there were pale cells reminiscent of those seen in germinal centres but lacking both mitotic figures and tingible bodies. (3) Structures closely resembling germinal centres but lacking either tingible bodies or mitotic figures.

The total numbers of germinal centres and rounded lymphoid clusters were ascertained in each section. Their sizes were determined using a calibrated eyepiece graticule; measurements of each structure were made in two axes at right angles to each other and the mean was calculated.

\section{Results}

\section{COMPARISON WITH HAMMAR'S DATA}

The percentages of thymic tissue occupied by cortex and medulla were determined in subjects in the following age groups: birth-5 years, 6-10 years, and 11-15 years. There were insufficient biopsies from subjects over 16 years of age to allow meaningful statistical evaluation. The results are shown in

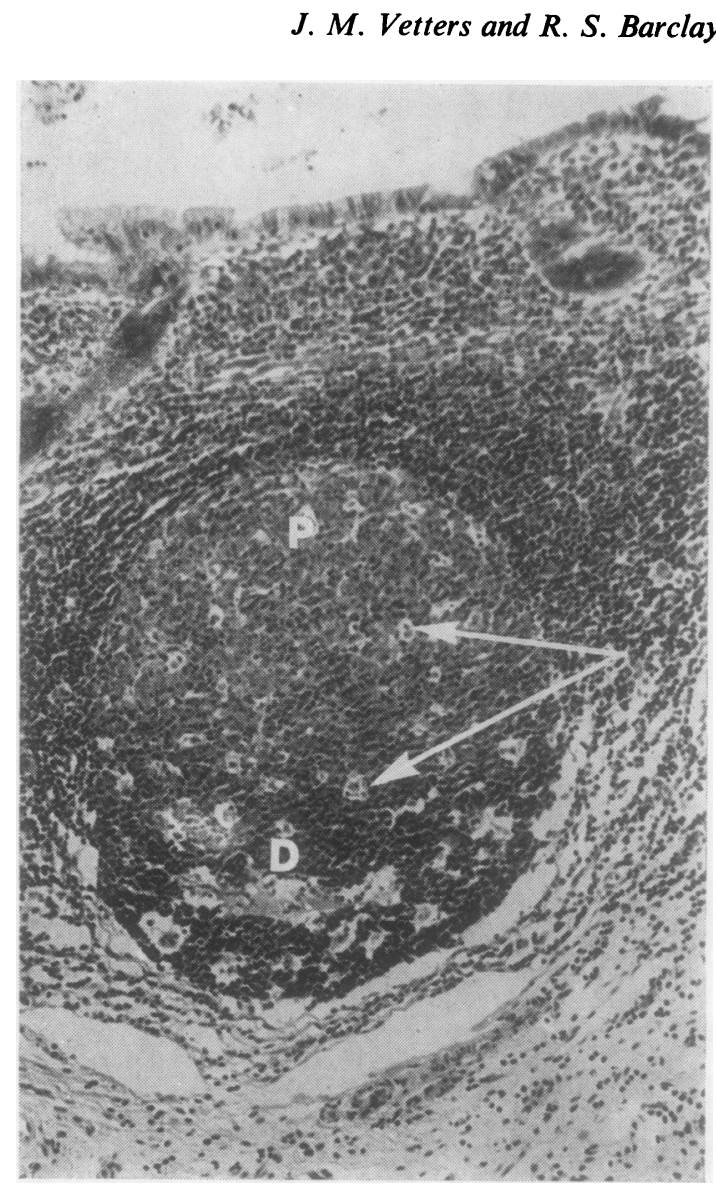

Fig 6 Polar orientation of appendicular germinal centre. The structural configuration of a normal germinal centre is seen. The luminal end (P) of the germinal centre is paler than the deeper pole (D). The lymphocytic cuff is present round the luminal pole but absent at the deep pole. Tingible bodies (arrowed) are seen throughout the pale centre but mitotic figures are present only on its deeper aspect (see also figs 7 and 8).

table II. It will be noted that in the first group there is a highly significant diminution in the amount of cortex compared with that in Hammar's subjects. In 0 addition, the birth-5 years and 11-16 years age $\sim$ groups show a significant increase in the percentage $\underset{\mathrm{W}}{N}$ of the thymus occupied by medulla. These figures 0 indicate stress-induced change of the thymus; the changes are most severe in the youngest subjects.

The implication is discussed below.

INCIDENCE OF GERMINAL CENTRES AND ROUNDED LYMPHOID CLUSTERS

Twelve individuals $(16 \%)$ had classical germinal $\frac{\Omega}{\mathbb{D}}$ centres in the thymus gland. Of these, seven $(9.3 \%)$ also had rounded lymphoid clusters. Of the remain- 


\begin{tabular}{|c|c|c|c|c|c|c|c|c|}
\hline \multirow[t]{2}{*}{ (Age yr) } & \multicolumn{4}{|c|}{ Percentage Gland Occupied by Cortex } & \multicolumn{4}{|c|}{ Percentage Gland Occupied by Medulla } \\
\hline & Hammar & Present Series & $t$ Test & Probability & Hammar & Present Series & t Test & Probability \\
\hline $\begin{array}{c}0-5 \\
6-10 \\
11-16\end{array}$ & $\begin{array}{l}56 \cdot 82 \pm 1 \cdot 73 \\
48 \cdot 56 \pm 1 \cdot 51 \\
45.5 \pm 1 \cdot 26\end{array}$ & $\begin{array}{l}49.61 \pm 1.25 \\
44.45 \pm 2.67 \\
41.37 \pm 2.63\end{array}$ & $\begin{array}{l}3.4597 \\
1.4364 \\
1.5813\end{array}$ & $\begin{array}{l}0.0005 \\
0.079 \\
0.062\end{array}$ & $\begin{array}{l}21.81 \pm 0.93 \\
27.37 \pm 1.04 \\
27.24 \pm 1.13\end{array}$ & $\begin{array}{l}29 \cdot 01 \pm 1 \cdot 11 \\
27 \cdot 35 \pm 1 \cdot 57 \\
32 \cdot 34 \pm 1 \cdot 58\end{array}$ & $\begin{array}{l}4 \cdot 5841 \\
0 \cdot 0089 \\
2 \cdot 4188\end{array}$ & $\begin{array}{l}0.00001 \\
0.497 \\
0.011\end{array}$ \\
\hline
\end{tabular}

Table II Comparison of Hammar's data with those of the present series

ing 63 subjects a further 17 had rounded thymus clusters and 46 had neither germinal centres nor rounded lymphoid clusters in the thymus glands.

Rounded lymphoid clusters appear to obliquely sectioned germinal centres. The evidence for this is as follows: (a) Serial sectioning of thymic tissue shows that the structures corresponding to rounded lymphoid clusters are germinal centres which have not been sectioned optimally. This is illustrated using serial sections of human thymus in fig 7 and diagrammatically in figure 8. (b) Statistical analysis using the $\chi^{2}$ test shows that the two occurred together more frequently than would be expected by chance $\left(\chi^{2}=4.55, \mathrm{P}<0.05\right)$. It is therefore reasonable to conclude that many of the structures identified as rounded lymphoid clusters are in fact nonoptimally sectioned germinal centres.

RELATIONSHIP OF AGE TO INCIDENCE OF GERMINAL CENTRES AND ROUNDED LYMPHOID CLUSTERS

Table III shows the incidence in each age group.

\begin{tabular}{llll}
\hline Age & $\begin{array}{l}\text { Number of } \\
\text { Subjects }\end{array}$ & $\begin{array}{l}\text { Number with } \\
\text { Germinal } \\
\text { Centres }\end{array}$ & $\begin{array}{l}\text { Number with } \\
\text { Rounded } \\
\text { Lymphoid } \\
\text { Clusters Only }\end{array}$ \\
\hline Under 1 year & 4 & 0 & 0 \\
1 & 2 & 0 & 0 \\
2 & 3 & 0 & 0 \\
3 & 4 & 0 & 0 \\
4 & 18 & 3 & 6 \\
5 & 12 & 4 & 1 \\
0 & 7 & 1 & 1 \\
7 & 7 & 1 & 2 \\
9 & 4 & 1 & 0 \\
12 & 2 & 1 & 1 \\
13 & 3 & 0 & 2 \\
14 & 2 & 0 & 1 \\
15 & 1 & 0 & 4 \\
$15+$ & 6 & 0 & 4 \\
\hline
\end{tabular}

Table III Incidence of germinal centres and rounded lymphoid clusters at different ages
Neither germinal centres nor rounded lymphoid clusters were found in children under 4 years of age. However, they occurred both in children over that age and in adults. In subjects under 16 years the combined incidence is approximately $38 \%(26 / 29)$ and in subjects between 17 and 39 years the incidence of rounded lymphoid clusters is $4 / 6$. No true germinal centres were seen in this group. There is a significant relationship between the ages of those with and without germinal centres and rounded lymphoid centres; the average age of those without the structures is 6 years and those with the structures is 8.6 years (Student's $t=1.739, P=0.043$ ). This is because of the absence of the structures in subjects under 4 years of age.

\section{SEASONAL VARIATION IN INCIDENCE OF REACTIVE LYMPHOID STRUCTURES}

It was found that the incidence of lymphoid structures varies with the season. The highest incidence occurred during the months November to February, When subjects under 4 years of age are excluded, 60 subjects remain. The monthly incidence in these subjects is shown in table IV; this variation is not statistically significant.

COMPARISON OF SIZE OF GERMINAL CENTRES WITH THOSE IN A GROUP OF PATIENTS WITH MYASTHENIA GRAVIS

The sizes of the all true germinal centres detected in the present series were compared with those found in comparable sections of thymus glands removed surgically from a group of 14 patients with myasthenia gravis. The mean size of the germinal centres in the present series was $217.0 \pm 19.9 \mu$ and the mean size of germinal centres in the patients with myasthenia gravis was $304 \cdot 8 \pm 11 \cdot 4 \mu$. The difference between these groups is statistically highly significant $(t=3.6715, \mathrm{P}<0.001)$.

\begin{tabular}{|c|c|c|c|c|c|c|c|c|c|c|c|c|}
\hline & Jan & Feb & Mar & $A p r$ & May & June & July & Aug & Sep & Oct & Nov & Dec \\
\hline $\begin{array}{l}\text { Positive } \\
\text { Negative }\end{array}$ & $\begin{array}{l}5 \\
3\end{array}$ & $\begin{array}{l}5 \\
2\end{array}$ & $\begin{array}{l}0 \\
2\end{array}$ & $\begin{array}{l}0 \\
2\end{array}$ & $\begin{array}{l}1 \\
3\end{array}$ & $\begin{array}{l}4 \\
2\end{array}$ & $\begin{array}{l}\mathbf{0} \\
\mathbf{0}\end{array}$ & $\begin{array}{l}1 \\
3\end{array}$ & $\begin{array}{l}0 \\
3\end{array}$ & $\begin{array}{l}3 \\
4\end{array}$ & $\begin{array}{l}7 \\
5\end{array}$ & $\begin{array}{l}2 \\
3\end{array}$ \\
\hline
\end{tabular}

Table IV Monthly incidence of thymic reactive structures 


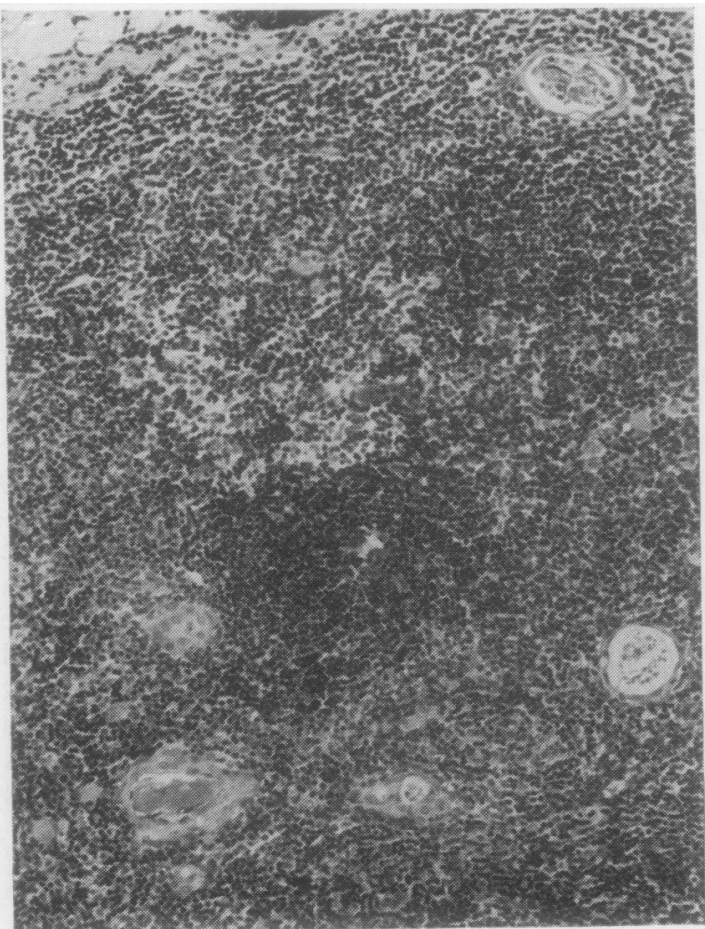

Fig 7a

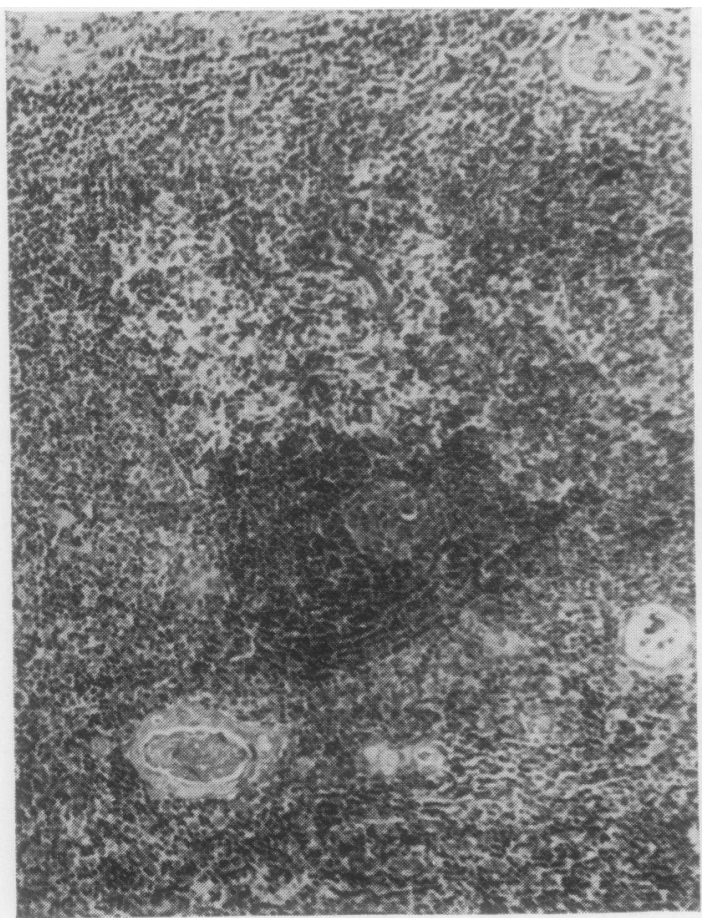

Fig $7 b$

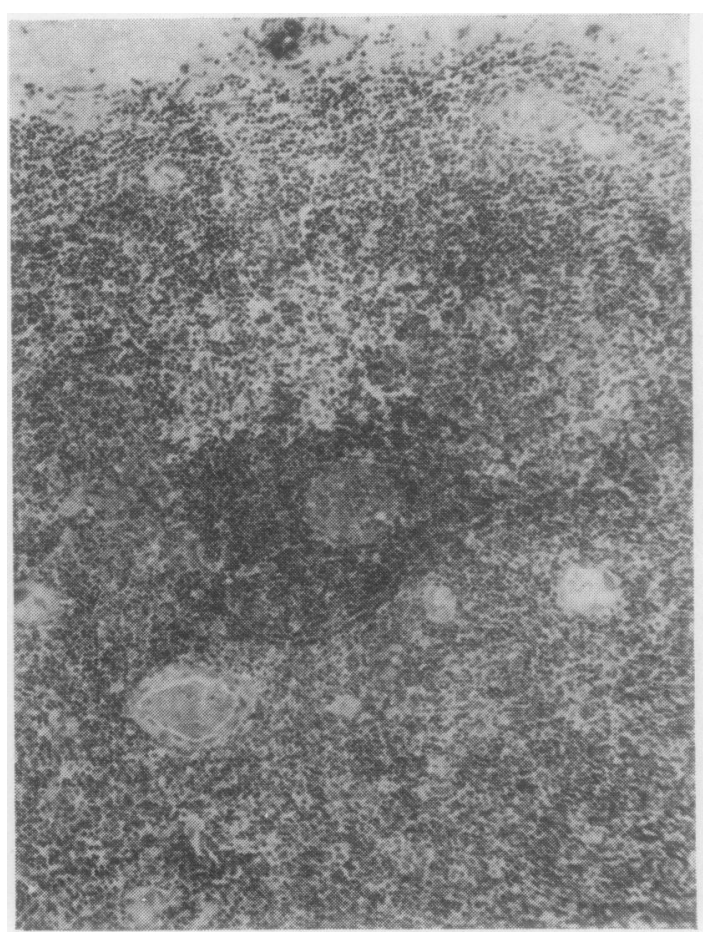

Fig 7c

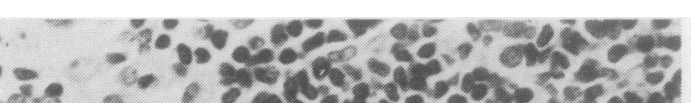
눈.

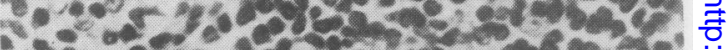

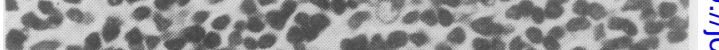

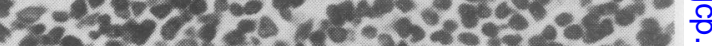

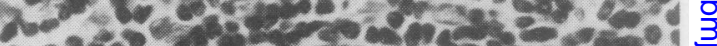

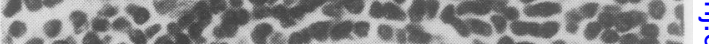

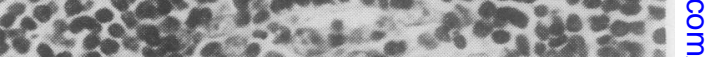

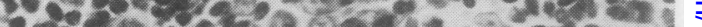

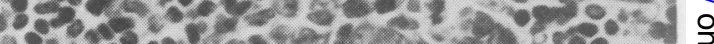

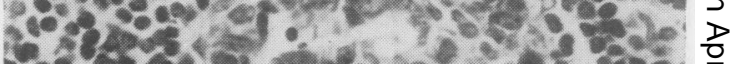

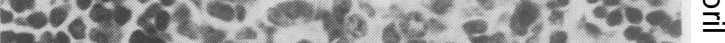

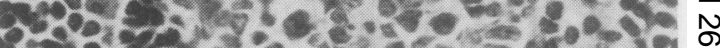

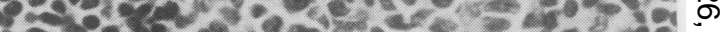

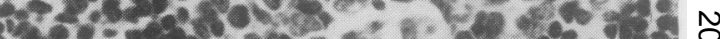

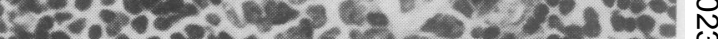
- a - 1.

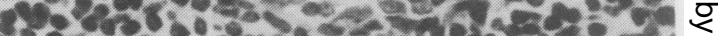

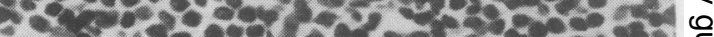

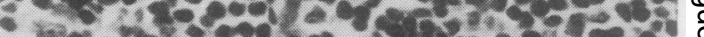

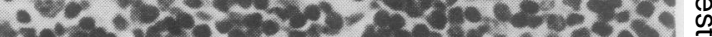

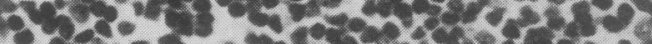

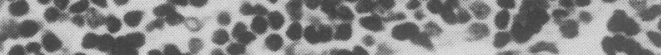
C12 -

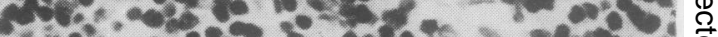

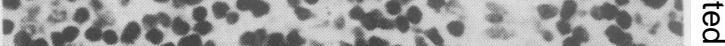

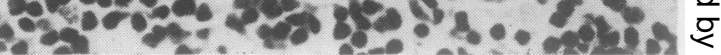

Fig 7d 


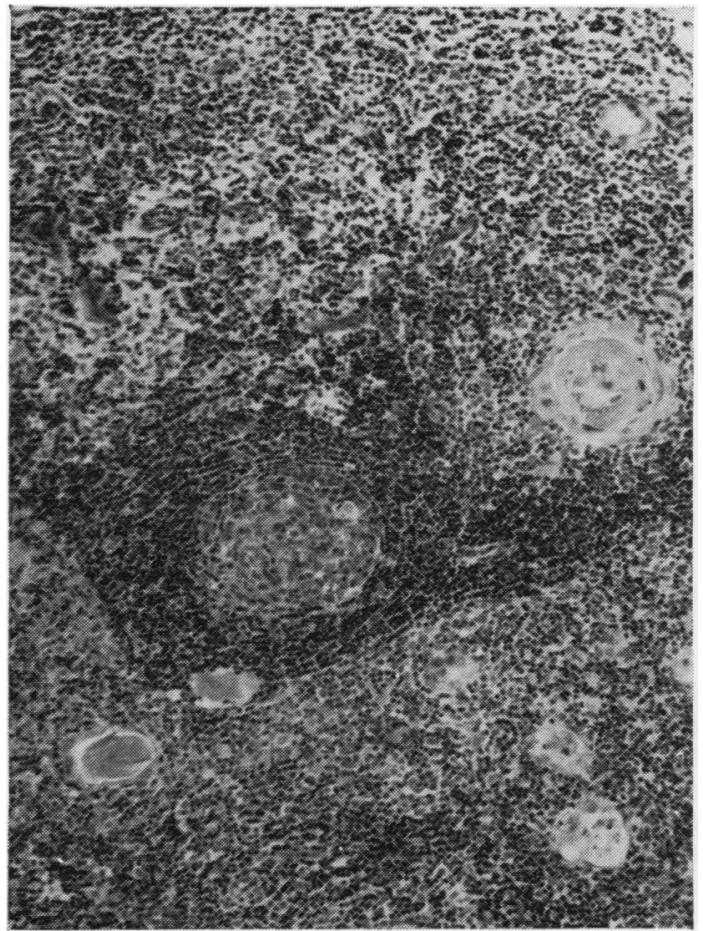

Fig 7e

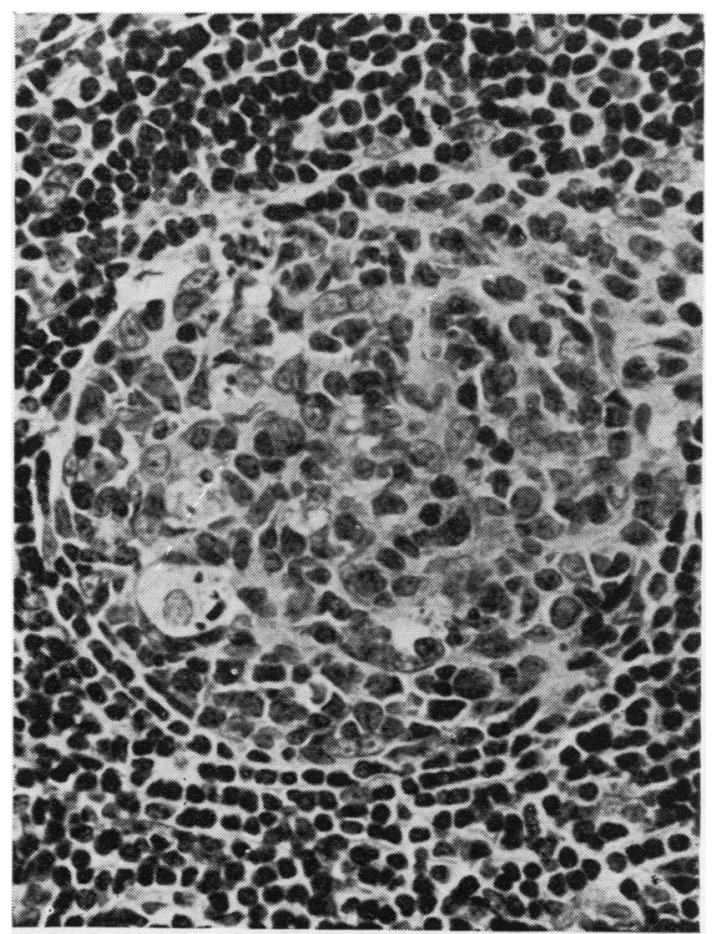

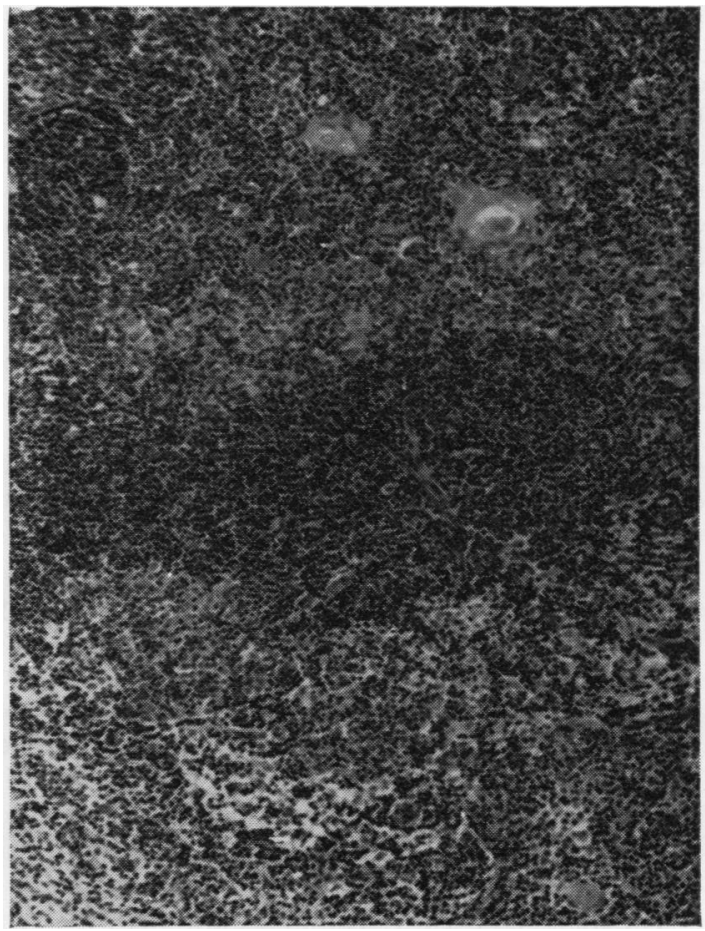

Fig $7 g$

Fig 7 Serial sections were made of thymic tissue removed from an apparently normal male. The illustrations are intended to demonstrate the similarity of the appearances in some levels to those seen in figures 2-5.

(a) A distinct cluster of lymphocytes is present. $\times 100$.

(b) At one end the lymphocyte cluster contains a circular clump of reticulum cells $12 \mu$ from (a) $\times 100$.

(c) The cluster of reticulum cells is now more distinct but is still very small $30 \mu$ from (a) $\times 100$.

(d) Detail of $(c)$. The pale centre contains a mitotic figure and tingible bodies. This is therefore a true germinal centre. $\times 400$.

(e) The pale centre is appreciably larger $72 \mu$ from (a) $\times 100$.

(f) Detail of (e). Only tingible bodies are seen in the pale centre; in the present study structures like this were counted as rounded lymphoid clusters. $\times 400$.

(g) The pale centre has now disappeared and only a dense cluster of lymphocytes remains $156 \mu$ from (a) $\times 100$.

Fig $7 f$ 


\section{Discussion}

COMPARISON WITH HAMMAR'S (1926) DATA From the observations of Sloan (1943) and Middleton (1967) it is known that stress causes a marked reduction in the incidence of thymic germinal centres. Further, study of the copious data obtained by Hammar $(1926,1929)$ shows that subjects who die after stressful illnesses have relatively less cortex and more medulla in the thymus gland than subjects who died suddenly after accidents. Therefore, in a study of the incidence of reactive structures in thymus glands it is best to use unstressed glands, ie, from subjects dying rapidly from accidental causes. Because of Scottish legal practice it was not practical to obtain such a series. Instead glands biopsied during operations to correct congenital cardiac lesions were used. In this case it is necessary to assess whether there is alteration of the percentage of the thymus glands occupied by cortex and medulla by comparing the results with those of Hammar (1926) who painstakingly quantitated glands of subjects who died suddenly from accidental causes. This comparison makes it possible to assess whether the glands are normal or show signs of stress-induced change.

The methods used by Hammar, although tedious, are accurate and differences between the present studies and his reports cannot be attributed to technical causes. It is true that Hammar obtained his material over 50 years ago when malnutrition and infectious diseases were more prevalent in European urban communities than today. Additionally, Hammar's subjects were exposed to the severe Scandinavian winters. Since malnutrition, cold, and infection are all causes of stress it is probable that any influence they would have had would have been to reduce the differences between the groups rather than accentuate them.

It is reasonable to conclude that since there is stress-induced atrophy in the thymus glands of patients with congenital heart disease the incidence of germinal centres is lower in them than in healthy subjects.

INCIDENCE OF GERMINAL CENTRES

The nomenclature and identification of reactive lymphoid structures (lymph follicles and germinal centres) in human thymus have been a source of difficulty to many workers, eg, Burnet and Mackay (1965), Middleton (1967), and Goldstein and Mackay (1969). Basically the problem is the classification of structures which do not fulfil all the histological criteria of germinal centres. Goldstein and Mackay (1967) discounted such structures whilst Burnet and Mackay (1965) considered them to be

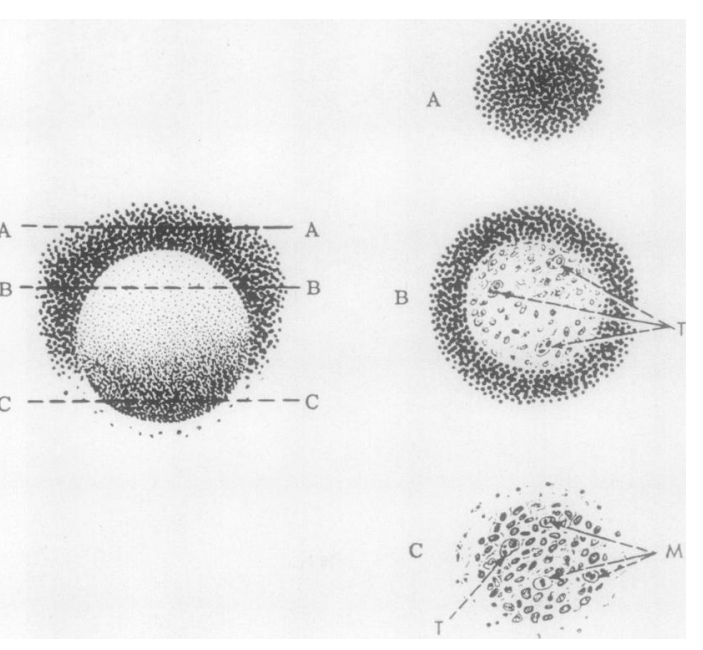

Fig 8 The large drawing on the left is a diagram of the polar arrangement of a germinal centre as seen in figure 6. Notice the lymphocytic cuff and pale centre with its pale upper portion and darker lower portion. The three drawings on the right illustrate the effect of sectioning of a germinal centre at levels $\mathrm{A}, \mathrm{B}$, and $\mathrm{C}$. Note the resemblance to the structures seen in figures 3-5. In this study the structures resembling those shown in $\mathrm{A}$ and $\mathrm{B}$ were counted as rounded lymphoid clusters and structures resembling $\mathrm{C}$ as germinal centres.

immature germinal centres. Middleton (1967) attempted to resolve the problem by cutting several sections when circumscribed clusters of medullary lymphocytes were found. When he found a cluster of pale central cells by this technique he counted the structure as a lymphoid follicle; mitotic figures and tingible bodies were not considered essential.

Habu et al (1971) concentrated their attention on lymphoid follicles which they defined as 'well demarcated dense accumulations of lymphocytes ... which seem to shrink away from the surrounding tissue'.

It is clear that because of the various criteria which have been used by different authors it is difficult to compare their data as presented. However, the demonstration by Millikin (1966) of the polar arrangement of human germinal centres helps to resolve the difficulty (fig 6). Sections of a germinal centre other than through the polar axis results in a variety of apperances, many of which do not fulfil the classical criteria used to identify germinal centres (figs 7 and 8).

In the present study these have been called rounded lymphoid clusters. Habu et al (1971) used the term lymphoid follicle to include both germinal centres and rounded lymphoid clusters. Middleton 
(1967) also used the term 'lymphoid follicle' but in a more restrictive way in that he ignored 'solid' clusters of lymphocytes. Burnet and Mackay (1965) used the term 'germinal centre' but included some structures not fulfilling all the criteria for germinal centres. Henry (1968) counted only classical germinal centres. The results of the various authors are conflicting (see table I).

Some of the variation may be due to the ages of the subjects examined. Lymphoid follicles and germinal centres are very infrequent in subjects over 40 years of age (Middleton, 1967; Habu et al, 1971). However, the principal causes of the discrepancies lie in two factors: (a) whether the glands examined came from stressed subjects, and $(b)$ the criteria used to identify germinal centres. These will be considered separately.

\section{Influence of stress}

Following the studies of Sloan (1943), Middleton (1967), and Habu et al (1971) (see table I) there can be no doubt that stress reduces or abolishes thymic germinal centres. When necropsy material is used failure to use only subjects who have died very rapidly has resulted in the difficulty in identifying thymic germinal centres. However, biopsies obtained during thoracic operations may also show alterations due to the stress caused by the disease (usually congenital heart disease) which necessitated the operation. The present study has shown that the percentage of the thymus occupied by cortex is decreased and the percentage occupied by medulla is increased in patients with congenital heart disease. These are the same alterations observed by Hammar (1929) in his studies of large numbers of subjects who had died from a wide variety of diseases. The alterations are most marked in the youngest subjects in ourseries and this is to be expected since they have the most severe cardiac lesions. It is therefore reasonable to conclude that the incidence of germinal centres and lymph follicles in patients operated on for congenital heart disease is lower than in normal subjects of corresponding age.

\section{Criteria used to identify germinal centres}

The classical features used to identify germinal centres are the presence of large cells with relatively pale cytoplasm surrounded by a cuff of lymphocytes. The pale cells must contain mitotic figures and there must also be phagocytosed nuclear debris (tingible bodies). Some authors have adhered rigidly to these criteria, eg, Goldstein and Mackay (1967) and Henry (1968). Some have used more liberal interpretations and others have not defined the structures they called germinal centres, eg, Bhathal and Campbell
(1967). Naturally those who adopted stringent criteria found appreciably fewer cases with thymic germinal centres. However, by cutting serial sections we have shown that many structures which these authors would have discounted are in fact true germinal centres which have been sectioned obliquely so that all the histological features are not visible in one histological section. It is our view that the structures which do not meet the full criteria for germinal centres (which we have termed rounded lymphoid clusters to distinguish them from the classical germinal centres) may be legitimately counted as germinal centres. This being the case, the overall incidence of germinal centres in the group of subjects examined ranging up to 40 years of age is approximately $39 \%$. Since we have shown that the subjects studied had stress involution of the thymus as demonstrated by alteration of the percentages of their thymus glands occupied by cortex and medulla it is reasonable to conclude that the incidence is even higher than this and that Middleton's figure, though disputed by others, is likely to be correct.

Figure 8 was kindly drawn by $\mathrm{Mr} \mathrm{R}$. Callander, Medical Illustrations Unit, University of Glasgow. This project was aided by the Macmillan Research Funds of the University of Glasgow.

\section{References}

Anderson, R. M. (1956). The thymus gland in myasthenia gravis. Med. J. Aust., 1, 919-921.

Bhathal, P.S., and Campbell, P. E. (1965). Eosinophil leucocytes in the child's thymus. Aust. Ann. Med., 14, 210-213.

Burnet, F. M. (1962). The immunological significance of the thymus; an extension of the clonal selection theory of immunity. Aust. Ann. Med., 11, 79-91.

Burnet, F. M., and Mackay, I. R. (1965). Histology of a thymus removed surgically from a patient with severe untreated systemic lupus erythematosis. J. Path. Bact., 89, 263-270.

Castleman, B., and Norris, E. H. (1949). The pathology of the thymus in myasthenia gravis. Medicine (Baltimore), 28, 27-58.

Goldstein, G., and Mackay, I. R. (1967). The thymus in systemic lupus erythematosus; a quantitative histopathological analysis and comparison with stress involution. Brit. med. J., 2, 475-478.

Habu, S., Kameya, T., and Tamaoki, N. (1971). Thymic lymphoid follicles in autoimmune diseases. I Quantitative studies with special reference to myasthenia gravis. Keio. J. Med., 20, 4556.

Hammar, J. A. (1926). Die Menschenthymus in Gesundheit und Krankheit: I. Das normal Organ. Z. Zellforsch., Suppl. 6.

Hammar, J. A. (1929). Die Menschenthymus in Gesundheit und Krankheit: II. Das Organ unter anormalen Korperverhaltnissen. $Z$. Zellforsch., Suppl., 16.

Henry, K. (1968). The thymus in rheumatic heart disease. Clin. exp. Immunol., 3, 509-523.

Middleton, G. (1967). The incidence of folicular structures in the human thymus at autopsy Aust. J. exp. biol. med. Sci., 45, 189. 199.

Millikin, P. O. (1966). Anatomy of germinal centers in human lymphoid tissue. Arch. Path., 82, 499-505.

Okabe, H. (1966). Thymic lymph follicles; a histopathological study of 1356 autopsy cases. Acta path. jap., 16, 109-130.

Sloan, H. E., Jr. (1943). The thymus in myasthenia gravis. Surgery, 13, 154-174. 